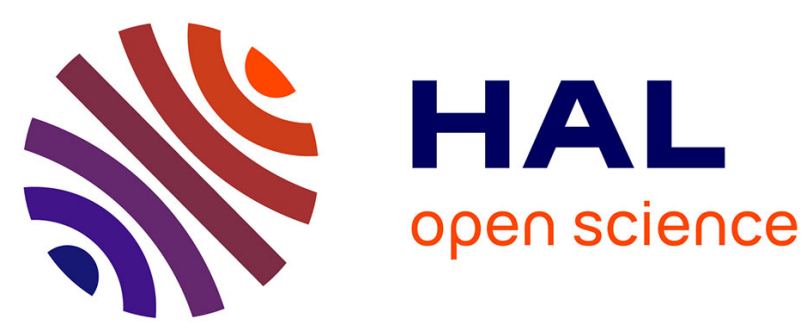

\title{
High Bandwidth Microgripper with Integrated Force Sensors and Position Estimation for the Grasp of Multi-stiffness Microcomponents.
}

\author{
Bilal Komati, Cédric Clévy, Philippe Lutz
}

\section{To cite this version:}

Bilal Komati, Cédric Clévy, Philippe Lutz. High Bandwidth Microgripper with Integrated Force Sensors and Position Estimation for the Grasp of Multi-stiffness Microcomponents.. IEEE/ASME Transactions on Mechatronics, 2016, 99, 10.1109/TMECH.2016.2546688 . hal-01303481

HAL Id: hal-01303481

https://hal.science/hal-01303481

Submitted on 18 Apr 2016

HAL is a multi-disciplinary open access archive for the deposit and dissemination of scientific research documents, whether they are published or not. The documents may come from teaching and research institutions in France or abroad, or from public or private research centers.
L'archive ouverte pluridisciplinaire HAL, est destinée au dépôt et à la diffusion de documents scientifiques de niveau recherche, publiés ou non, émanant des établissements d'enseignement et de recherche français ou étrangers, des laboratoires publics ou privés. 


\title{
High Bandwidth Microgripper with Integrated Force Sensors and Position Estimation for the Grasp of Multi-stiffness Microcomponents
}

\author{
Bilal Komati, Cédric Clévy, Member, IEEE and Philippe Lutz, Member, IEEE
}

\begin{abstract}
At the microscale, small inertia and high dynamics of microparts increase the complexity of grasping, releasing and positioning tasks. The difficulty increases especially because the position, the dimensions and the stiffness of the micropart are unknown. In this paper, the use of a microgripper with integrated sensorized end-effectors with high dynamic capabilities is proposed to perform stable and accurate grasps of multistiffness microcomponents. A dynamic nonlinear force/position model of the complete microgripper while manipulating a microcomponent is developed. The model takes into consideration not only free motion and constrained motion, but also, contact transitions which is a key issue at the microscale due to the predominance of surface forces. It enables to estimate the position of the microgripper's end-effectors, the contact position of the microcomponent and the force applied on the microcomponent. Using the proposed microgripper and its model, both of the gripping forces are measured and the position of each of the microgripper's endeffectors is estimated. This enables to perform a stable grasp of the micropart by providing force and position feedback. Moreover, using the developed microgripper and its model, the characterization of the microcomponent can be performed by estimating its dimensions and its stiffness.
\end{abstract}

Index Terms-Micromanipulation, microassembly, grasp, piezoelectric actuator, force sensing, piezoresistive force sensor, position estimation, stiffness measurement, model, characterization, force control.

\section{INTRODUCTION}

D URING the last decade, the need of micro and nanotechnologies has grown [1]. Recent works have shown that microassembly is a possible approach to fabricate complex hybrid 3-D microsystems [2], [3]. They also show the need of high speed manipulation [4] where pick-and-place tasks were performed in $1 \mathrm{~s}$. Nevertheless, manipulation of microcomponents is a challenging task due to microscale specificities. These specificities are mainly manifested by the difficulty of sensors integration at this scale, the very small inertia of microsystems, their high dynamics and the predominance of surface forces (such as capillary, electrostatic and van der Waals forces) and contact forces (such as pull-off forces), but also, the lack of precise models. Therefore, the interaction between micromanipulation tools and the microcomponents is less predictable and much more complex than at the macroscale. In literature, it has been shown that forceguided microassembly [5], large displacement range and high

The authors are with FEMTO-ST Institute, AS2M department, Univ. Bourgogne Franche-Comté, Univ. de Franche-Comté/CNRS/ENSMM, 24 rue Savary, F-25000 Besançon, France, (e-mails: bilal.komati@femto-st.fr; cclevy@femto-st.fr; philippe.lutz@femto-st.fr). bandwidth for both sensing and actuation constitute relevant approaches to perform complex microassembly tasks [6]. The measurement of microscale forces is critical to obtain local and useful information like contact and adhesion forces. Previous works have shown the importance of measuring both of gripping forces to guarantee the stability of the component during microassembly [7], [8]. Sensing and actuation bandwidths are notably critical especially for contact transition. Indeed, when a micropart is placed between microgripper fingers, a contact may appear between one finger and the micropart before the other which can lead to the loss of the micropart due to the high dynamics of the microparts. Therefore, actuation and force measurement with high bandwidth from both sides is critical to succeed the grasping of the micropart by stopping the movement of the finger in contact with the micropart if the other finger has not reached the contact yet. Consequently, innovative handling tools and strategies that ensure gripping, releasing, and precise positioning of microparts using force, including contact detection and position measurements, are very promising topics and are investigated in this paper.

Many researches have concentrated on the design of novel microgrippers due to their importance for handling microobjects. The state of the art of two-fingers microgrippers is focused on three points: the actuation and sensing principles [3], [7]-[13], the number of active (actuated) fingers and sensing fingers [14]-[20] and their control [21]. Thus, several existing microgrippers with force sensing are compared in Fig. 1. The comparison between the microgrippers concern the number of active fingers, number of force sensors, force sensing range and displacement range. Fig. 1 shows that there is a lack of microgrippers with two active fingers and two integrated sensors with big sensing range including both microscale forces and contact forces (from hundreds of $\mathrm{nN}$ up to hundreds of $\mu \mathrm{N}$ ) with high bandwidth for sensing and actuation. Specific microgrippers are required to achieve complex, stable and dexterous microassembly tasks [24]. Previous work shows the importance of having microgrippers with two multi-DOF actuated fingers to perform a complex and dexterous microspectrometer assembly [25]. Regarding the sensor and actuation bandwidth, few works provide dynamic characterization of the microgrippers. Hence, it is difficult to compare between the dynamic performances of existing microgrippers. Nevertheless, it is known that piezoelectric actuation and piezoresistive sensing present high dynamical capabilities when they are compared to electrostatic or electrothermal actuation and capacitive force sensing. Indeed, very high 


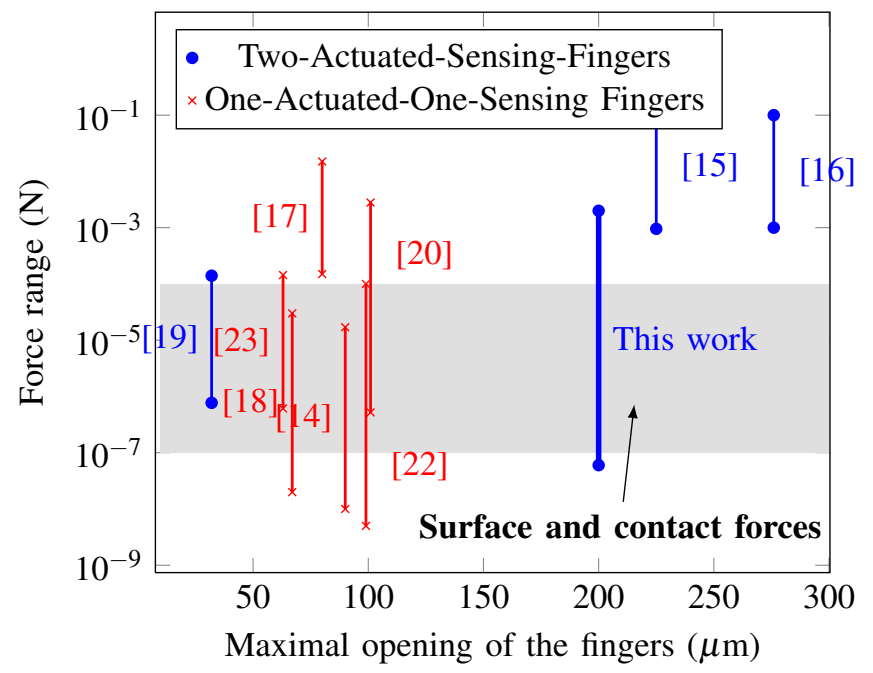

Fig. 1: Comparison between existing microgrippers with integrated force sensors in terms of displacement range and force sensing range.

bandwidth up to $100 \mathrm{kHz}$ can be achieved using piezoresistive force sensors [26] where much lower bandwidths appear using other techniques such as $45 \mathrm{~Hz}$ [27] and $2.2 \mathrm{kHz}$ [28].

The objective of this paper is to propose a microgripper which can be used to perform more a complex, stable and dexterous microassembly by providing large and precise sensing and displacement ranges as shown in Fig. 1. Indeed, a twosmart-fingers-microgripper (TSFM) is proposed. Each of the two fingers is an active finger (based on piezoelectric actuator) with an integrated force sensor (exploiting the piezoresistive effect). In order to detect contact/non-contact transitions and to improve positioning of manipulated components, the position of the microgripper's end-effectors have to be measured or online estimated. To tackle the technological challenge of integrating both force and position sensors, we propose to estimate the position of the microgripper end-effectors online through a dynamic nonlinear model of the TSFM. The developed model enables the use of the TSFM for both dynamic and static applications by tracking both of the forces and positions.

To reach the objective of the paper which is to develop a new and characterized TSFM, the following paper organization is proposed. The specifications and the implementation of the Two-Sensing-Fingers-Microgripper (TSFM) are presented in Section II. The complete dynamic nonlinear model of the TSFM is developed in Section III leading to develop an estimator for the position of the microgripper's end-effectors. The model parameters are identified experimentally in Section IV. In section V, the model developed is tested experimentally up to potential use. Finally, Section VI concludes the paper.

\section{SPeCificAtions, Design AND IMPlementation of THE TWO-SMART-FINGERS-MICROGRIPPER (TSFM)}

The objective of this section is to present the specifications, the design and the fabrication of the proposed TSFM. The microgripper should be able to move with a large range and small resolution in order to be able to cover wide range of microassembly tasks. The microgripper displacement range is fixed to be from several $\mathrm{nm}$ to hundreds of $\mu \mathrm{m}$ as shown in Fig. 1. The force sensor should measure forces which are predominant at the microscale. These forces are between hundreds of $\mathrm{nN}$ and hundreds of $\mu \mathrm{N}$ [29], [30]. In addition, in microassembly context, previous works show that during microassembly, forces can reach several $\mathrm{mN}$ [8]. The dynamic behavior of both actuation and sensing is an important issue at the microscale. Indeed, interactions exist between the microgripper and microcomponents with small inertia leading to very high dynamics of microcomponents. Nevertheless, Most of the microgrippers use actuation and sensing techniques enabling small bandwidth. This fact limits the use of these microgrippers for high dynamics applications and for high speed microassembly. Consequently, and to satisfy the actuation, the sensing ranges and high bandwidth, the solution proposed in this paper is to develop a two-fingered microgripper where each finger is composed of a piezoelectric actuator [13] and MEMS based piezoresistive force sensor with doped silicon strain gauges [31]. Piezoelectric actuation and piezoresistive force sensing techniques are used to provide high bandwidth actuation and sensing. The monolithic fabrication of such microgripper with piezoelectric material and silicon based piezoresistive force sensor stills a challenging task. In order to prevent high complexity of fabrication, piezoelectric actuator and piezoresistive force sensor are assembled. The force sensor is small where its dimensions are $1 \mathrm{~mm} \times 100 \mu \mathrm{m} \times 10 \mu \mathrm{m}$ and has a resolution of $60 \mathrm{nN}$, a sensing range of $2 \mathrm{mN}$ and a bandwidth of $8 \mathrm{kHz}$. The design of the whole TSFM is shown in Fig. 2.

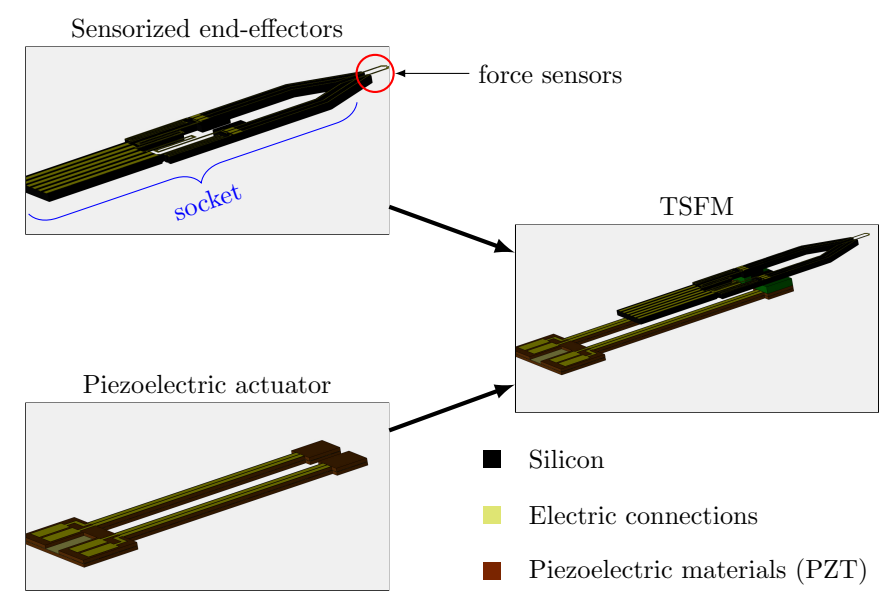

Fig. 2: Integration of the sensorized end-effectors into a piezoelectric actuator to realize the TSFM.

The force sensor is fixed on a rigid $350 \mu \mathrm{m}$ thick silicon layer called socket. A principle scheme of the TSFM is presented in Fig. 3 where the actuator, the rigid part and the sensing parts are shown. The two fingers are supposed to be identical.

Several steps and precautions have to be considered in order to realize the TSFM. First, the components are very fragile, so special care needs to be done in order not to break the components. Second, mechanical fixation should be done 


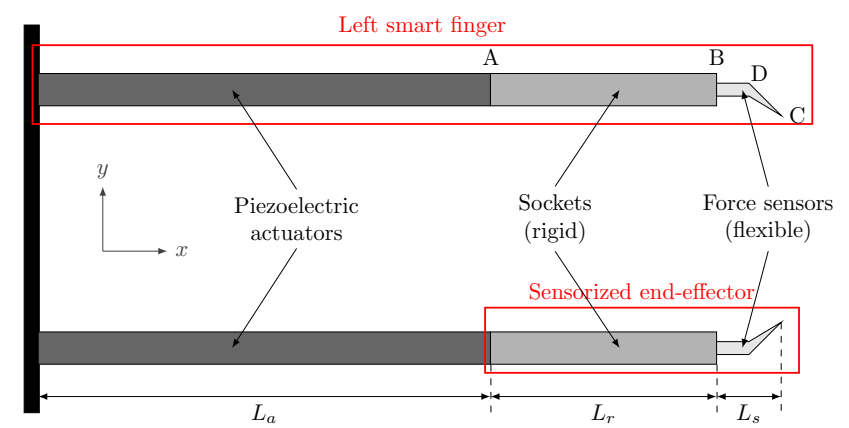

Fig. 3: Complete scheme of the two-smart-fingers microgripper (TSFM).

between the actuator and a fixed support on the one hand and between the end-effector and the actuator on the other hand. Third, electric connections are required to apply voltage to the actuator and to retrieve the force sensor signal to an electronic circuit. Fourth, an electronic circuit needs to be done to condition the signal of the force sensor. The final result of the assembly is the packaged TSFM shown in Fig. 4, showing the piezoelectric actuators, the sensorized end-effector and a zoom on the piezoresistive force sensors.

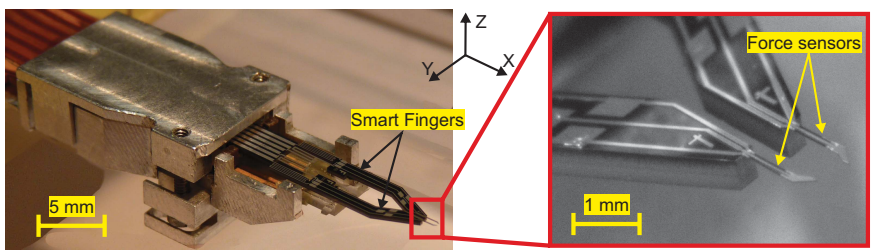

Fig. 4: Two-smart-fingers microgripper (TSFM).

The proposed TSFM has presented interesting actuation and sensing performances when it is compared to existing microgrippers with integrated force sensors. Each finger of the TSFM is composed of an actuator and force sensor. The characteristics of the actuators and sensors are summarized in Table I. The stiffness of the force sensor is much smaller than that of the actuator. This is due to the need of flexibility in the force sensor in order to measure small forces.

\begin{tabular}{|c|l|c|}
\hline \multirow{3}{*}{ Displacement } & Resolution & $10 \mathrm{~nm}$ \\
\cline { 2 - 3 } & Displacement range & $100 \mu \mathrm{m}$ \\
\cline { 2 - 3 } & Stiffness & $1100 \mathrm{~N} / \mathrm{m}$ \\
\hline \multirow{3}{*}{ Force sensing } & Resolution & $60 \mathrm{nN}$ \\
\cline { 2 - 3 } & Sensing range & $2 \mathrm{mN}$ \\
\cline { 2 - 3 } & Stiffness & $130 \mathrm{~N} / \mathrm{m}$ \\
\hline \multirow{2}{*}{ Bandwidth } & Actuation & $>1 \mathrm{kHz}$ \\
\cline { 2 - 3 } & Sensing & $8.52 \mathrm{kHz}$ \\
\hline
\end{tabular}

TABLE I: Performances of the TSFM fingers.

\section{Dynamic Nonlinear Model of the TSFM}

The objective of the proposed TSFM is to perform complex micromanipulation and microassembly tasks. The microgripper is composed of active materials with integrated force sensors and has interactions with the microparts to be manipulated. Thus, the voltage, the force and the displacement are three critical parameters which should be known at the same time to succeed the task. The voltage is known because it is the input of the TSFM and the force is measured through sensors. However, the displacement of the end-effectors is unknown and has to be estimated online. For this reason, a dynamic model has to be developed to complete the required information of voltage, force and displacement which is critical to predict the dynamic behavior of the TSFM and later to control the TSFM. Therefore, a dynamic nonlinear model is developed in this section to estimate the position of the end-effectors. The microgripper being composed of three elements (actuator, rigid part and force sensor), each will be modeled separately, then the whole model of the TSFM will be developed.

\section{A. Manipulation scenarios}

Two scenarios can be faced during the modeling of the whole TSFM:

- free motion step where the two fingers of the TSFM move without contact,

- constrained motion step where there is a contact between each finger and the manipulated micropart.

One model will be developed for both cases in the following.

In a typical micromanipulation case, the microgripper's fingers move until they enter in contact with the microcomponent. The considered scenario is that one of the fingers of the microgripper enters in contact with the micropart and brings the micropart towards contact with the second finger in order to manipulate the micropart. The force measured by the force sensor increases once a contact appears $\left(F_{s} \neq 0\right)$. Fig. 5 shows four different cases for the system:

(a) initial state where no motion of the finger and no applied voltage $(V=0$ and $U=0)$,

(b) free motion of the actuator without any contact,

(c) just at transition between free and constrained motion of the finger $\left(F_{s}=0\right)$,

(d) constrained motion which happens after the contact $\left(F_{s} \neq 0\right)$.

Notice that the deflection of the actuator is always considered to be in a simple deflection mode as shown in Fig. 5-(d). This assumption is done because the actuator is 10 times stiffer than the force sensor which means that the deflection due to contact force will be mainly at the force sensor.

The method to determine the model of the system is summarized in Fig. 6. First, the model of the piezoelectric actuator is presented alone taking into consideration the voltage applied on the actuator, the force and the moment as inputs of the system and the actuator's tip displacement $y_{A}$ and bending angle $\alpha_{A}$ as outputs. Then, the end-effector is modeled as a lever system with length $L=L_{r}+L_{s}$ with a mass-springdamper-system (see section III-C) where the outputs of the model are the displacement of the end-effector's tip C, $y_{C}$, and gripping force $F_{g}$ at the force sensor's tip C. The last two outputs (i.e. $y_{C}$ and $F_{g}$ ) are then transformed using lever system to the actuator as force and moment. Indeed, an applied force, $F_{s}=-F_{g}$ on the force sensor tip $\mathrm{C}$ induces reaction force and 

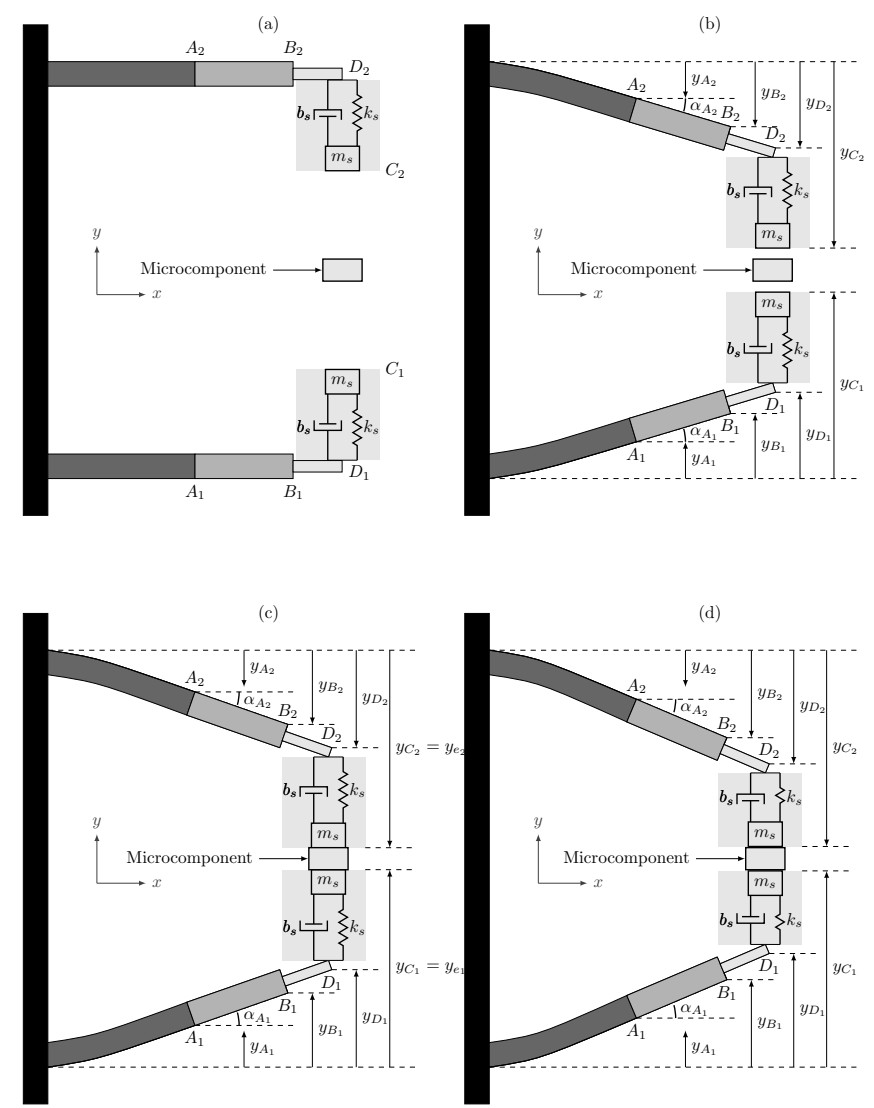

Fig. 5: Equivalent dynamic scheme of the TSFM in four cases: (a) initial state $\left(F_{s}=0\right.$ and $\left.U=0\right)$ (b) free motion with an applied voltage to the finger $\left(F_{s}=0\right.$ and $\left.U \neq 0\right)$, (c) just at the transition between free motion and constrained motion $\left(F_{s}=0\right)$ and $(\mathrm{d})$ constrained motion after contact $\left(F_{s} \neq 0\right)$.

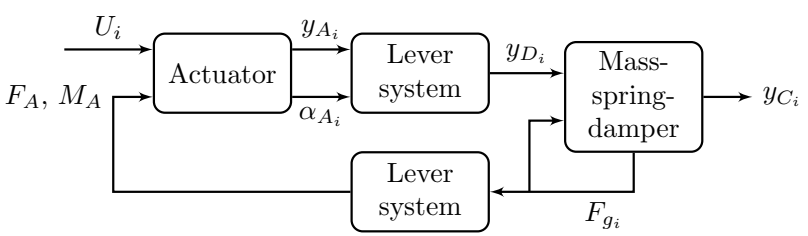

Fig. 6: Block diagram to show the method to determine the free motion model of the TSFM. Index $i$ refers to each of the two fingers: $i=1$ referes to finger 1 and $i=2$ refers to finger 2.

a moment on the actuator's tip A as follows:

$$
\left\{\begin{array}{l}
F_{A}=-F_{s}+m_{s} \ddot{y}_{C}=F_{g}+m_{s} \ddot{y}_{C} \\
M_{A}=-L F_{s}=L F_{g}
\end{array}\right.
$$

where $F_{g}$ is the gripping force applied by the force sensor on the micropart and $F_{S}$ is the force measured by the force sensor. In the following, the model of each part of the TSFM is developed according to Fig. 6.

\section{B. Dynamic nonlinear model of the piezoelectric actuator}

Extensive researches have been made in the past years on the piezoelectric actuators including their design [10], [32], models [33] and control [34], [35]. Several models have been developed for the piezoelectric actuators in literature [36][40]. The main differences between the models are the method to model the nonlinearities and the dynamics of the system. In this section, a nonlinear dynamic model of the piezoelectric actuator is developed based on models presented in the stateof-the-art.

The model of the piezoelectric actuator developed in this paper consists of developing the expressions of the two outputs of the actuator $\left(y_{A}\right.$ and $\alpha_{A}$ shown in Fig. 5) where the applied voltage, force and moment on the tip A will be considered the inputs of the model $\left(U, F_{A}\right.$ and $\left.M_{A}\right)$.

In this paper, several assumptions will be considered to develop the model of the piezoelectric actuator:

1) the dynamic behavior of the actuator is modeled by a linear second order transfer function $D(s)$ with a static gain of 1 (i.e. $D(0)=1$ ). Although the linear part of the actuator can be described by a higher order transfer function, a second order transfer function is sufficient to represent the dynamics and its use is popular in several applications [39], [41], [42];

2) the model of nonlinearities will be limited to the ratedependent hysteresis of the piezoelectric actuator. Consequently, the creep will not be modeled because its action occurs only in static domain. Moreover, the force sensing of the system provides some feedback to the system leading to taking the creep into consideration in the model when the object is manipulated;

3) the rate dependent hysteresis is modeled by a nonlinear static part (using Bouc-Wen hysteresis model) followed by the dynamics of the actuator as proven in [41], [43].

Based on these assumptions (issued from trade-off choices), the resulting model of the rate-dependent nonlinearities of the piezoelectric actuator, $\Gamma(U, s)$, can be given as follows:

$$
\Gamma(U, s)=H_{s}(U) \cdot D(s)
$$

where $s$ is the Laplace variable, $U$ is the applied voltage and $H_{s}(U)$ is an operator to represent a static hysteresis of the piezoelectric actuator modeled using Bouc-Wen hysteresis model. Bouc-Wen hysteresis model consists of a nonlinear first order differential equation mathematical model to describe the hysteresis of the system. The Bouc-Wen model has been modified in [39] to fit to the hysteresis of the piezoelectric actuator. It can be represented in the time domain by the following equation:

$$
\dot{H}_{S}(U)=\lambda \dot{u}(t)-\beta|\dot{u}(t)| H_{S}(t)-\gamma \dot{u}(t)\left|H_{S}(t)\right|
$$

where $H_{s}(t)$ is the operator of the Bouc-Wen hysteresis, $u(t)$ is the applied voltage on the actuator, $\lambda$ is a parameter which determines the amplitude of the hysteresis and $\beta$ and $\gamma$ are parameters which determine the shape of the hysteresis.

Based on models developed in [40], [41], [43], [44] and using (2), the model of the piezoelectric actuator can be written 
in the frequency domain as follows:

$$
\left\{\begin{array}{l}
y_{A}(s)=\left[d_{p} U-H_{s}(U)-s_{p} F_{A}-\frac{3}{2 L_{a}} s_{p} M_{A}\right] \cdot D(s) \\
\alpha_{A}(s)=\left[\frac{2}{L_{a}}\left(d_{p} U-H_{s}(U)\right)-\frac{3}{2 L_{a}} s_{p} F_{A}-\frac{3}{L_{a}^{2}} s_{p} M_{A}\right] \cdot D(s) \\
D(s)=\frac{1}{a s^{2}+b s+1}
\end{array}\right.
$$

where $s$ is the Laplace operator, $y_{A}$ and $\alpha_{A}$ are respectively the displacement (deflection) and the bending angle at the tip of the actuator $\mathrm{A} ; U$ is the applied voltage on the actuator; $F_{A}$ and $M_{A}$ are respectively the applied force and the applied moment on the tip $\mathrm{A} ; d_{p}$ is the piezoelectric constant; $s_{p}$ is the elastic constant; $L_{a}$ is the length of the actuator; $a$ and $b$ are two parameters of the transfer function $D(s)$ which models the dynamic behavior of the actuator; $H_{S}(U)$ is an operator to represent the Bouc-Wen hysteresis as shown in (3).

\section{Model of the sensorized end-effector}

The end-effector is composed of two parts: a rigid part made of $350 \mu \mathrm{m}$ thick silicon layer (called socket) and the force sensor which has $10 \mu \mathrm{m}$ of thickness. The rigid part tip of the end-effector is the point B (see Fig. 3) and the force sensor tip is the point $\mathrm{C}$ (see Fig. 3).

The rigid part can be considered as a lever system with a length of $L_{r}$. Between points B and C of Fig. 3, there exists a flexible zone to measure the force. Then, the structure between $\mathrm{B}$ and $\mathrm{C}$ is modeled as a lever system with length $L_{s}$ and a mass-spring-damper system with mass $m_{s}$, damping $d_{s}$ and stiffness $k_{s} . L_{s}$ is the length of the force sensor between $\mathrm{B}$ and $\mathrm{C}$.

Then, the complete sensorized end-effector is modeled as a lever system with length $L=L_{r}+L_{S}$ and a mass-spring-damper system. The tip D is the tip of the lever system with length $L=L_{r}+L_{s}$. The end-effector equivalent system is represented in Fig. 7 showing the tips A, B, C and D and the mass-springdamper.

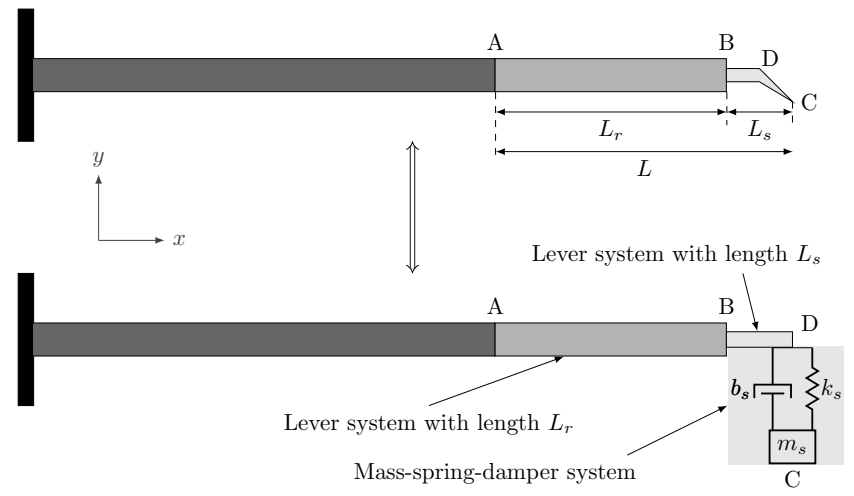

Fig. 7: Equivalent scheme of the sensorized end-effector.

\section{Model of the whole TSFM}

In the case considered in this document, the force is applied at the tip of the force sensor C. Replacing (1) in (4), the following can be deduced:

$$
\left\{\begin{aligned}
Y_{A}(s)= & {\left[d_{p} U-H_{s}(U)-\left(1+\frac{3 L}{2 L_{a}}\right) s_{p} F_{g}-m_{s} s_{p} s^{2} Y_{C}\right] D(s) } \\
\alpha_{A}(s)= & {\left[\frac{2}{L_{a}}\left(d_{p} U-H_{s}(U)\right)-\left(\frac{3}{2 L_{a}}+\frac{3 L}{L_{a}^{2}}\right) s_{p} F_{g}-\right.} \\
& \left.\frac{3}{2 L_{a}} m_{s} s_{p} s^{2} Y_{C}\right] D(s)
\end{aligned}\right.
$$

The position of the point $\mathrm{D}, y_{D}$, is calculated as follows:

$$
y_{D}=y_{A}+L \sin \alpha_{A} \approx y_{A}+L \alpha_{A}
$$

because we are working with small deflections and then $\sin \alpha_{A} \approx \alpha_{A}$. Replacing (5) in (6), the following can be deduced:

$$
\begin{aligned}
Y_{D}= & {\left[\left(1+\frac{2 L}{L_{a}}\right)\left(d_{p} U-H_{s}(U)\right)-\left(1+\frac{3 L}{L_{a}}+\frac{3 L^{2}}{L_{a}^{2}}\right) s_{p} F_{g}-\right.} \\
& \left.-\left(1+\frac{3 L}{2 L_{a}}\right) m_{s} s_{p} s^{2} Y_{C}\right] D(s)
\end{aligned}
$$

In this case, as a force is applied at the tip of the force sensor which is modeled as a mass-spring-damper system, the applied force at the tip of the force sensor can be given as follows:

$$
F_{s}=-F_{g}=m_{s} \ddot{y}_{C}(t)+b_{s} \dot{\Delta L}+k_{s} \Delta L
$$

where $\Delta L=y_{C}-y_{D}$. Then, replacing $\Delta L$ in (8), the following can be deduced:

$$
F_{s}=-F_{g}=m_{s} \ddot{y}_{C}+b_{s}\left(\dot{y}_{C}-\dot{y}_{D}\right)+k_{s}\left(y_{C}-y_{D}\right)
$$

On the other hand, using (9), the following can be deduced:

$$
Y_{C}=\frac{b_{s} s+k_{s}}{m_{s} s^{2}+b_{s} s+k_{s}} Y_{D}-\frac{1}{m_{s} s^{2}+b_{s} s+k_{s}} F_{g}
$$

Replacing (7) in (10), the displacement $Y_{C}$ can be given as follows:

$$
Y_{C}=G_{u}(s)\left(d_{p} U-H_{s}(U)-G_{f}(s) F_{g}\right)
$$

where:

$$
\left\{\begin{aligned}
G_{u}(s) & =\frac{b_{1} s+b_{0}}{a_{4} s^{4}+a_{3} s^{3}+a_{2} s^{2}+a_{1} s+a_{0}} \\
G_{f}(s) & =\frac{c_{2} s^{2}+c_{1} s+c_{0}}{b_{1} s+b_{0}} \\
\dot{H}_{s}(U) & =\lambda \dot{U}-\beta|\dot{U}| H_{s}(U)-\gamma \dot{U}\left|H_{s}(U)\right|
\end{aligned}\right.
$$

where:

$$
\left\{\begin{array}{l}
a_{0}=k_{s}, a_{1}=b k_{s}+b_{s}, a_{4}=a m_{s} \\
a_{2}=a k_{s}+b b_{s}+m_{s}+\left(1+\frac{3 L}{2 L_{a}}\right) b_{s} m_{s} s_{p} \\
a_{3}=b m_{s}+a b_{s}+\left(1+\frac{3 L}{2 L_{a}}\right) b_{s} m_{s} s_{p} \\
b_{0}=\left(1+\frac{2 L}{L_{a}}\right) k_{s}, b_{1}=\left(1+\frac{2 L}{L_{a}}\right) b_{s} \\
c_{0}=1+\left(1+\frac{3 L}{L_{a}}+\frac{3 L^{2}}{L_{a}^{2}}\right) s_{p} k_{s} \\
c_{1}=b+\left(1+\frac{3 L}{L_{a}}+\frac{3 L^{2}}{L_{a}^{2}}\right) s_{p} b_{s} \\
c_{2}=a
\end{array}\right.
$$


The models defined in (11) is developed to estimate the position of the microgripper's end-effectors without adding additional external position sensors.

\section{IDENTIFICATION OF THE MODEL PARAMETERS OF THE TSFM}

In order to identify the parameters of the TSFM, the experimental setup used will be firstly introduced. Then, the parameters of the sensorized end-effectors will be identified followed by the parameters of the piezoelectric actuator.

\section{A. Experimental Setup}

Several scenarios are tested in this section. Thus, different experimental setups are used. However, experimental setups generally include a TSFM, position and force sensors and positioning stages. TSFM has a displacement range of 100 $\mu \mathrm{m}$ for each finger and force sensing range going from $60 \mathrm{nN}$ to $2 \mathrm{mN}$ for each force sensor. Position sensors are two laser Keyence sensors with $20 \mathrm{~nm}$ of resolution and $250 \mu \mathrm{m}$ of sensing range. They are used to measure the displacements of the TSFM fingers (points A and B). A force sensor FT-S270 from FemtoTools with a measuring range of $2000 \mu \mathrm{N}$ and a resolution of $0.4 \mu \mathrm{N}$ is used as reference sensor to measure the stiffness of the actuators and to calibrate the force sensors integrated in the TSFM. It comprises a probe tip of $3 \mathrm{~mm}$ in length and $50 \mu \mathrm{N}$ in thickness that moves along its main direction once a force is applied at its tip. The displacement is converted into a voltage thanks to a capacitive variation measured by a dedicated circuit. The force sensor is mounted on a microrobotic structure composed of a fine positioning stage and a rotation stage. The fine positioning stage is a P-611.3 NanoCube with $100 \mu \mathrm{m}$ range and $1 \mathrm{~nm}$ resolution. The rotation stage, a SmarAct SR-3610-S with 1.1 $\mu^{\circ}$ resolution, is used to adjust the perpendicularity of contact between the reference force sensor and the force sensors of the TSFM. These two motion devices are equipped with internal position sensors and are closed loop controlled. The reference force sensor is moved using the positioning stage towards the actuators or piezoresistive force sensor in order to determine the stiffness of the actuator or the characteristics of the piezoresistive force sensors. All actuators and positioning stages are controlled and the voltage acquisition of the sensors are performed via a dSpace 1104 acquisition board with a sampling frequency of $20 \mathrm{kHz}$. The experimental setup used for each identification step will be presented when presenting the steps.

\section{B. Identification of the sensorized end-effectors parameters}

The parameters consist of the length of the lever system $L$, the mechanical parameters of the two force sensors $m_{s}, d_{s}$ and $k_{s}$ and their sensitivity coefficients. The parameters of the two piezoresistive force sensors are identified experimentally before integrating the force sensors in the microgripper due to the difficulty of estimating the parameters of the force sensors after the integration and especially the dynamic parameters.

The length of the end-effector is determined by the designed mask used for the microfabrication. However, in order to determine the dynamic behavior of the sensor, a response of the force sensor is tested in free vibrations. Thus, a rigid object fixed on a microrobotic positioning stage enters in contact with the tip of the force sensor and applies a preload force of 150 $\mu \mathrm{N}$ for $t>0$ and at time $t=0$ the positioning stage is taken off abruptly to separate the contact. The free vibrations of the force sensor are registered using a sampling frequency of $20 \mathrm{kHz}$ (which is the maximal sampling frequency of the dSpace1104 used). Oscillations occur as shown in Fig. 8 before the signal stabilizes to zero. The force sensor can be modeled as a second order system with damping. A Fast Fourier Transform (FFT) is applied to the acquisition signal in order to determine precisely the natural frequency of the force sensor. The result of the FFT is shown in Fig. 8. The natural frequency, $f_{0}$, of the system is then determined to be $8520 \mathrm{~Hz}$ and a damping coefficient $\xi=0.006$. The force sensor being modeled as a mass-spring-damper system, the parameters $m_{s}$, $b_{s}$ and $k_{s}$ are identified and their values are shown in Table II. Also a sensitivity of $200 \mu \mathrm{N} / \mathrm{V}$ is obtained for the force sensors (for once refer to [31] which details the experimental procedure followed to identify it).
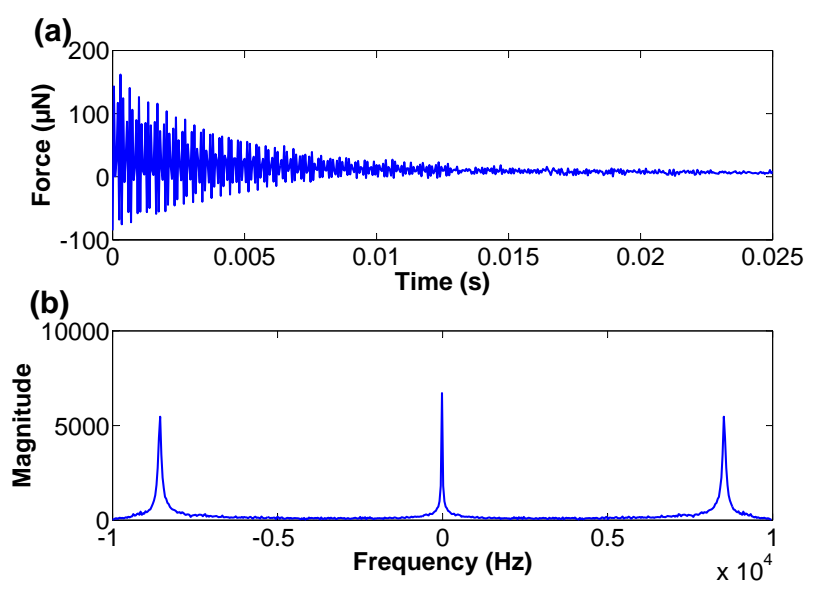

Fig. 8: The time signal and the FFT signal of the signal measured by the force sensor when free vibrations are applied to the force sensor.

\section{Identification of the actuator parameters}

After the identification of the parameters of the two piezoresistive force sensors, the parameters of the two piezoelectric actuators are identified in this section. The parameters are identified after the integration of the piezoresistive force sensors in the TSFM in order to take into consideration the effect of adding the force sensor to the actuator which influences the dynamic response of the actuator. The identification process concerns the identification of the parameters $d_{p}, s_{p}, \lambda, \beta, \gamma$, $a$ and $b$ shown in (4) and (3). The first five parameters can be identified in static mode while the others are identified dynamically.

1) Identification of the static parameters $d_{p}, \lambda, \beta$ and $\gamma$ in free motion:: In this case, a voltage is applied to the piezoelectric actuator and the displacement of the TSFM tip B 
is measured using Keyence Laser sensor without any contact between the actuator and the microcomponent (step (b) of Fig. 5). The experimental setup used is shown in Fig. 9-(a). To identify these parameters, a sine wave with a frequency of $0.1 \mathrm{~Hz}$ and an amplitude of $100 \mathrm{~V}$ is applied to the actuator. The frequency $0.1 \mathrm{~Hz}$ is chosen in order to minimize the dynamic part of the actuator [41], $D(s)$, and to identify the static parameters. The amplitude of the sine wave $100 \mathrm{~V}$ is chosen to identify the parameters for the external loop of the hysteresis and then the model is validated for the internal loops. The displacement is measured at the tip B and not at the tip A due to the too small workspace at point A. For this reason, the model of the displacement at point $\mathrm{B}$ is calculated by (7) after replacing $Y_{B}$ by $Y_{D}$ and $L$ by $L_{r}$ as follows:

$$
\begin{aligned}
Y_{B}= & {\left[\left(1+\frac{2 L_{r}}{L_{a}}\right)\left(d_{p} U-H_{s}(U)\right)-\left(1+\frac{3 L_{r}}{L_{a}}+\frac{3 L_{r}^{2}}{L_{a}^{2}}\right) s_{p} F_{g}\right.} \\
& \left.-\left(1+\frac{3 L_{r}}{2 L_{a}}\right) m_{s} s_{p} s^{2} Y_{C}\right] D(s)
\end{aligned}
$$

Then, the parameters of the actuator, $d_{p}, \lambda, \beta$ and $\gamma$, defined in (4) can be identified using the nonlinear least square method in order to fit the experimental results of the displacement at the tip B with the model defined in (14) for the hysteresis external loop. The model is then tested for the internal loops. A comparison between the model and the experiments after the parameter estimation is shown in Fig. 9-(b) for three different amplitudes of the sine waves $(30 \mathrm{~V}, 60 \mathrm{~V}$ and $100 \mathrm{~V})$. Fig. 9(b) shows that the Bouc Wen hysteresis model used to model the hysteresis of the piezoelectric actuator is able to model both internal and external loops of the hysteresis. The maximal relative error is less than $10 \%$ for the internal loop of $30 \mathrm{~V}$ and less than $5 \%$ for the external loop. This was expected because the parameters $d_{p}, \lambda, \beta$ and $\gamma$ are calculated to fit the external loop.

2) Identification of the dynamic part $D(s)$ and the constants $a$ and $b$ of the actuator in free motion:: In this case, a step voltage is applied to the actuator and the displacement of the smart finger's tip B is measured using a Keyence sensor. The same experimental setup presented in Fig. 9-(a) is used to identify the dynamical part of the actuator. The dynamical response, $D(s)$, is identified using a normalized second order transfer function with a static gain of 1 as in (4). The parameters to be identified are $a$ and $b$. The normalized step responses of the model of the displacement of $Y_{B}$ given in (14) and the experimental measurements are compared in Fig. 10 after the estimation of the parameters $a$ and $b$. Fig. 10 shows that the choice of a second order transfer function to model the first mode of the dynamics of the actuator is sufficient despite the presence of some errors between the model and the experiments. The relative error is smaller than $10 \%$ which is an acceptable error of the trade off between the dynamics and model order.

Moreover, it has been shown in experiments that the parameters $a$ and $b$ of the second transfer function are quasiindependent of the amplitude of the applied voltage (several step responses with different amplitudes have been applied to the actuator). The maximal variation of parameters is $3 \%$

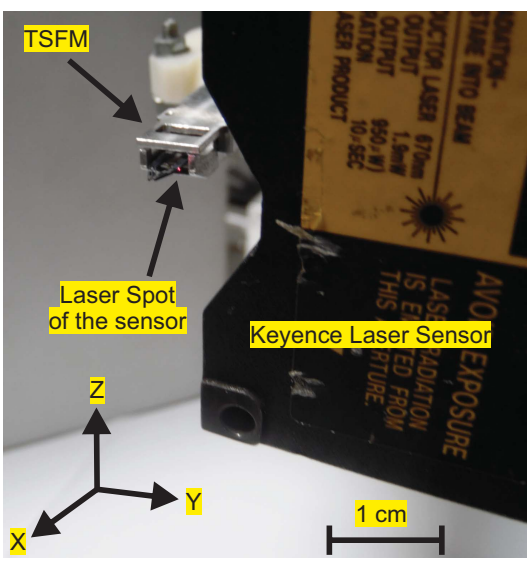

(a)

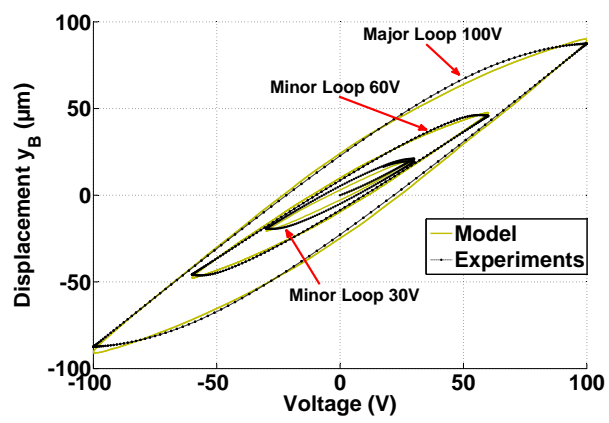

(b)

Fig. 9: (a) Experimental setup used for the identification of the static parameters of the actuators showing a displacement sensor measuring the actuator tip displacement; (b) Comparison between the Bouc-Wen static hysteresis model and experimental results for many sine voltages with three different amplitudes $30 \mathrm{~V}, 60 \mathrm{~V}$ and $100 \mathrm{~V}$ at a frequency $0.1 \mathrm{~Hz}$.

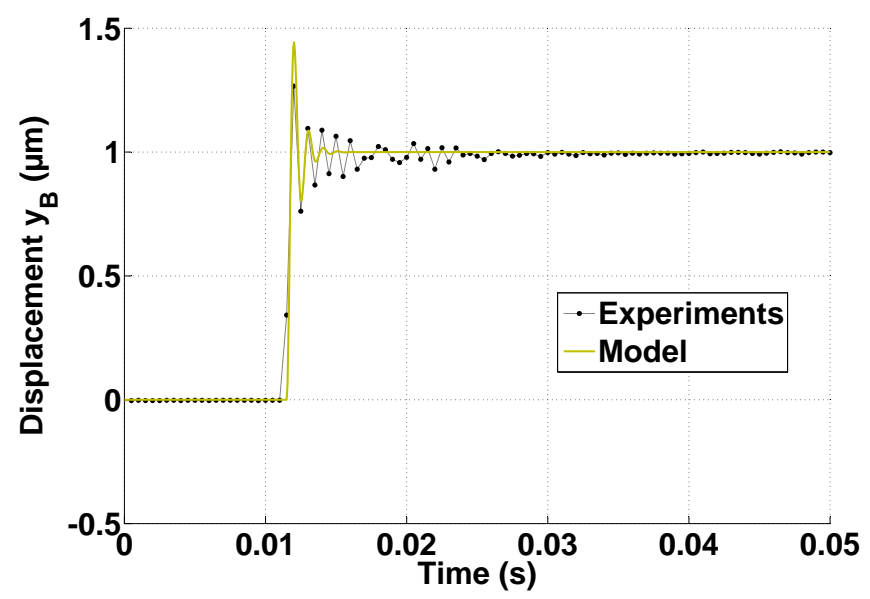

Fig. 10: Comparison between the normalized step responses of the model of the displacement of $Y_{B}$ given in (14) and the experimental measurements of $Y_{B}$.

which is known in literature. The whole model of the actuator will be validated in section $\mathrm{V}$. 


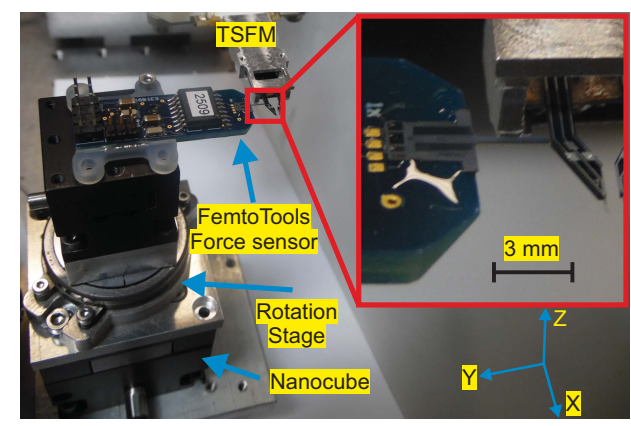

(a)

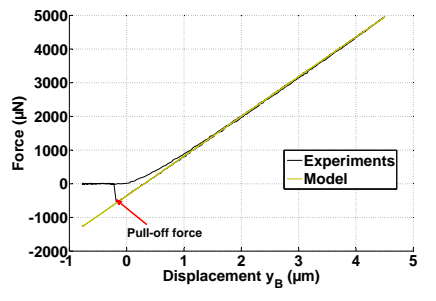

(b)

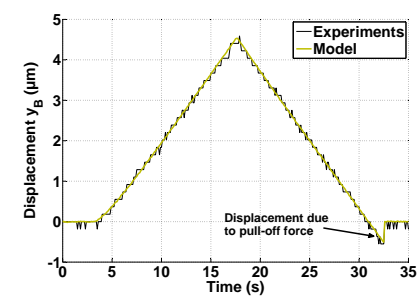

(c)
Fig. 11: Experimental setup and results of the identification of the actuator's elastic constant $s_{p}$ : (a) experimental setup, (b) comparison between the measurement and the model of the force relative to the displacement leading to the identification of $s_{p}$, (c) comparison between the model and the experimental results of the displacement of the tip B $y_{B}$ when a force is applied at the tip B after identifying $s_{p}$.

3) Identification of the elastic parameter $s_{p}$ of the actuator: In this case, the reference force sensor from FemtoTools is mounted on a sensorized NanoCube micropositioning stage to come into contact with the piezoelectric actuator's tip B as shown in Fig. 11-(a). Due to the small operation zone, the force is applied at the tip B because it is difficult to apply the force on the tip A directly. Then using (7) (when no voltage is applied and static behavior is considered), the model at tip $\mathrm{B}$ can be written as follows:

$$
Y_{B}=-\left(1+\frac{3 L_{r}}{L_{a}}+\frac{3 L_{r}^{2}}{L_{a}^{2}}\right) s_{p} F_{g}
$$

Thus, according to (15), the elastic constant $s_{p}$ can be estimated using the measurements of the force applied on the tip $\mathrm{B}, F_{g}$ and the displacement of the tip B, $y_{B}$. Fig. 11-(b) and 11-(c) compare respectively the measured force and displacement with the estimated force and displacement using the model in (15) after replacing the identified value of $s_{p}$. The model estimates precisely the position without errors in Fig. 11-(c). Regarding the force estimation in Fig. 11-(b), errors up to hundreds of $\mu \mathrm{N}$ appear when the force sensor approaches to the microgripper finger due to the pull-in effect. However, the error converges rapidly to zero after contact and the model is able to estimate precisely the force.

All the identified parameters are summarized in Table II.

\begin{tabular}{|c|c|c|c|}
\cline { 2 - 4 } \multicolumn{1}{c|}{} & Parameters & Left Finger & Right Finger \\
\hline \multirow{4}{*}{ Actuator } & $d_{p}(\mu \mathrm{m} / \mathrm{V})$ & 0.77 & 0.78 \\
\cline { 2 - 4 } & $s_{p}(\mathrm{~m} / \mathrm{N})$ & $9.1 \times 10^{-4}$ & $8.5 \times 10^{-4}$ \\
\cline { 2 - 4 } & $\lambda$ & 0.43 & 0.39 \\
\cline { 2 - 4 } & $\beta$ & $10.8 \times 10^{-2}$ & $11.1 \times 10^{-2}$ \\
\cline { 2 - 4 } & $\gamma$ & $7.5 \times 10^{-3}$ & $3.5 \times 10^{-3}$ \\
\cline { 2 - 4 } Force sensor & $a$ & $2.5 \times 10^{-8}$ & $2.5 \times 10^{-8}$ \\
\cline { 2 - 4 } & $b$ & $8 \times 10^{-5}$ & $8 \times 10^{-5}$ \\
\cline { 2 - 4 } & $m_{s}(\mathrm{Kg})$ & $1.8 \times 10^{-6}$ & $1.79 \times 10^{-6}$ \\
\cline { 2 - 4 } & $b_{s}(\mathrm{~N} \cdot \mathrm{s} / \mathrm{m})$ & $7 \times 10^{-4}$ & $6.98 \times 10^{-4}$ \\
\cline { 2 - 4 } & $k_{s}(\mathrm{~N} / \mathrm{m})$ & 128 & 130.8 \\
\cline { 2 - 4 } & Sensitivity $(\mathrm{V} / \mu \mathrm{N})$ & $6 \times 10^{-3}$ & $5.1 \times 10^{-3}$ \\
\hline
\end{tabular}

TABLE II: The values of the identified parameters of each of the two fingers.

\section{EXPERIMENTAL VALIDATION OF THE MODEL OF THE TSFM}

In this section, the model developed in section III is compared to experiments. Then several application using this microgripper will be presented.

\section{A. Validation of the dynamical model of the hysteresis of the actuator in free motion}

In this case, sine waves with different frequencies are applied to move the TSFM fingers while measuring the displacement of the tip B using the same experimental procedure in Fig. 9-(a). The experimental measurements are compared with the model of the actuator after identification of the parameters. The results of the comparison are shown in Fig. 12 which shows that the model is able to estimate the position including the dynamic hysteresis of the actuator. The model can estimate the actuator displacement for several frequencies with errors less than $10 \%$. The $10 \%$ error can be reached for high dynamics with minor loop hysteresis.
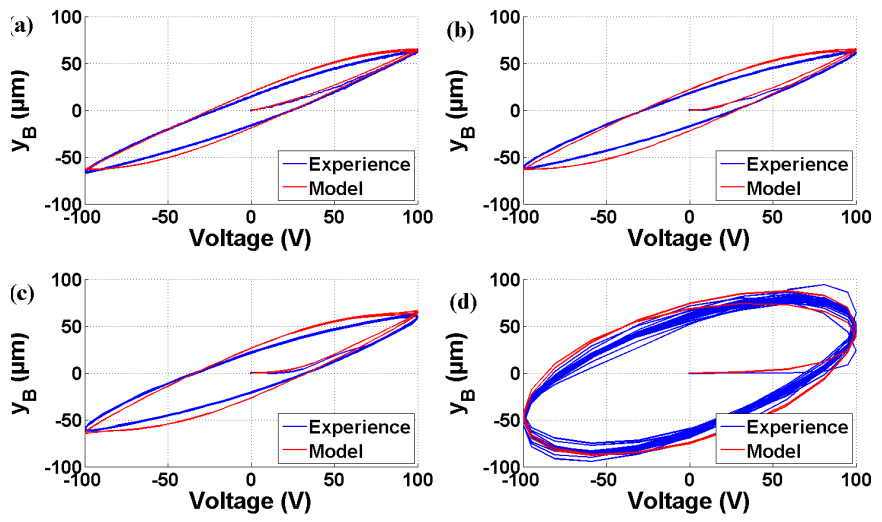

Fig. 12: Comparison between the displacement model of the tip B $y_{B}$ and experimental results for sine voltages with an amplitude of $100 \mathrm{~V}$ and with different frequencies where no force is applied: (a) $10 \mathrm{~Hz}$, (b) $50 \mathrm{~Hz}$, (c) $100 \mathrm{~Hz}$ and (d) $500 \mathrm{~Hz}$.

\section{B. Validation of the model of the whole TSFM}

A sine wave is applied to move the TSFM fingers. The displacement of the TSFM tip C is estimated using (11). 
Initially, no contact exists between the fingers and micropart (contact force is null and the fingers are in a free motion). Then, a contact happens at $U=44 \mathrm{~V}$ (Fig. 13), the system switches to constrained motion, the force starts to increase and the shape of the displacement changes after the contact. Then, at $U=50 \mathrm{~V}$, the force starts to decrease until separating the contact at $U=35 \mathrm{~V}$. The model and experiments are compared in Fig. 13 where both free motion model and constrained motion are shown. The model developed in (11) estimates
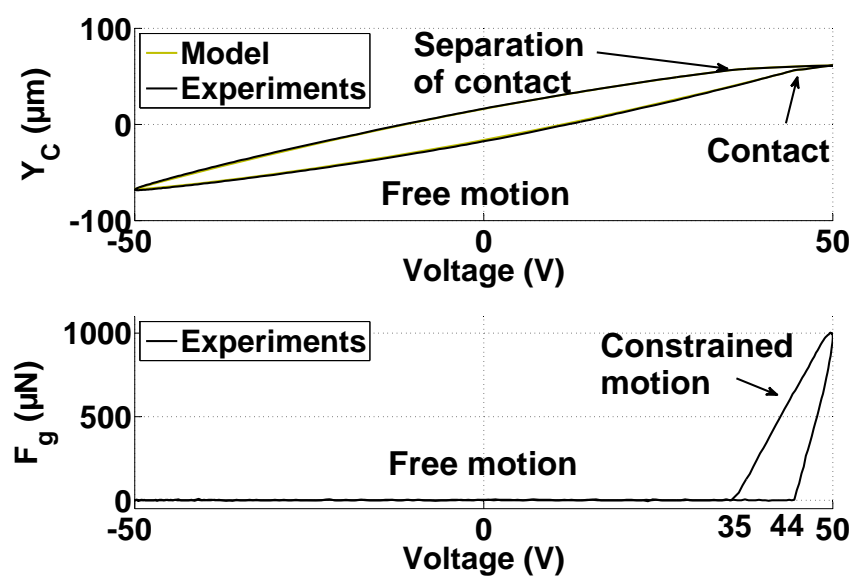

Fig. 13: Comparison between the model of the displacement of the TSFM tips C given in (11) and experimental measurements. The measurement force is also shown.

precisely with errors less $5 \%$ for both free motion model and constrained motion. Thus, the model developed in (11) to estimate the position of the TSFM fingers is validated experimentally.

C. Estimation of the location of the micropart between the fingers of the TSFM and measurement of the width of the micropart

The location of the micropart is estimated using the model defined in (11) and the force information. When a non zero force appears in one of the force sensors signals, the position of the end-effector corresponding to the non zero force information corresponds to the location of the micropart from one side between the fingers of the TSFM. The same procedure is repeated using the other finger of the TSFM to locate the micropart form the other side between the fingers of the TSFM. This position information is of great interest because it enables to know the initial shape of the micropart to be able to apply the desired force and to verify the safety of the micropart after manipulation. Notice that due to the force sensor noise which is less than $2 \mu \mathrm{N}$, a threshold of $5 \mu \mathrm{N}$ is fixed to set a non zero force information.

To validate this method, a flexible micropart, with width $300 \mu \mathrm{m}$, is placed between the fingers of the TSFM. The width of the micropart is known by the designed fabrication mask. Using Fig. 13, the location of the end-effector's tip C where the force $F_{g}$ becomes bigger than the threshold $5 \mu \mathrm{N}$ is $62.42 \mu \mathrm{m}$ and using the other finger, the location is $39.4 \mu \mathrm{m}$.
The initial gap between the two fingers is $400 \mu \mathrm{m}$, then the measured width of the micropart is:

$$
w=400-(62.42+39.4)=298.18 \mu \mathrm{m}
$$

The error on the estimation is less than $2 \mu \mathrm{m}$. The same experiment is repeated for several microparts (different sizes, varying form, different location between the fingers and different stiffness) and the errors on the estimation were always less than $5 \mu \mathrm{m}$ in the worst case where the model errors are maximal.

\section{Stiffness measurement}

Using the TSFM, the stiffness of the micropart can also be online estimated which is an important issue for manipulation and automation. Based on the gripping force measurement from both sides and the end-effectors displacement estimation from both sides, the stiffness of the micropart can be estimated using the following equation:

$$
\hat{k}_{e}=\frac{F_{g}}{\delta}
$$

where $\hat{k}_{e}$ is the estimated stiffness of the micropart, $F_{g}$ is the measured gripping force from both sides and $\delta$ is the total deformation of the micropart from both sides.

Using this method, three optical microparts made of silicon with different dimensions, as those presented in [2] where a spring element exists in the micropart, have been used for stiffness measurement where the errors of estimation have been less than $5 \%$ as shown in Table III. It enables to cover wide range of stiffness for microparts.

\begin{tabular}{|c|c|c|c|}
\hline Stiffness & Measured (N/m) & Estimated (N/m) & Error \\
\hline Micropart 1 & 12.1 & 11.7 & $3 \%$ \\
\hline Micropart 2 & 72.5 & 71.05 & $2 \%$ \\
\hline Micropart 3 & 469 & 445.55 & $5 \%$ \\
\hline
\end{tabular}

TABLE III: Comparison between the measured and estimated stiffnesses for three microparts.

\section{CONCLUSION}

The objective of this paper has been to propose a microgripper for dexterous, accurate, complex and high dynamics microassembly tasks. For this reason, a new integrated microgripper with sensorized end-effectors is designed and calibrated. Each finger of the microgripper is composed of a piezoelectric actuator and a sensorized end-effector leading to what has been called Two-Smart-Fingers-Microgripper (TSFM). The performances of this TSFM are very promising thanks to the actuation range going from nm up to $100 \mu \mathrm{m}$ and sensing range going from $60 \mathrm{nN}$ and up to $2 \mathrm{mN}$. These performances are carried out by each finger. The microgripper also presents high bandwidth for both actuation (more than $1 \mathrm{kHz})$ and force sensing $(8.5 \mathrm{kHz})$ which is promising for dynamic applications. A dynamic force/position model of the complete microgripper has been developed taking into consideration the free and constrained motion scenarios as well as non contact/contact transition. The model provides an 
online estimation of the displacement of the microgripper's end-effectors leading to model the contact transition. This microgripper enables the manipulation of microcomponents whose size and stiffness are unkown a priori. Some applications of the microgripper have been tested in this paper using the measurement of gripping forces and the estimation of the microgripper's end-effectors. This estimation enables to estimate online micropart's width and stiffness which appears as a key point for micromanipulation purposes. The error on the estimation of the micropart width was less than $5 \mu \mathrm{m}$ and the stiffness was less than $5 \%$.

The presented microgripper can be used for a wide range of applications starting from teleoperated microassembly and going to the full automation of the microassembly. It enables to perform more complex tasks than existing microgrippers by adding the possibility of measuring both of the gripping forces and the displacements of the end-effectors which is of great interest in micromanipulation and microassembly. Characterization of microparts is another possible application of the proposed microgripper.

Future works consist of using the microgripper to achieve automated microassembly tasks.

\section{ACKNOWLEDGMENT}

These works have been funded by the Franche-Comté region, supported by the Labex ACTION project (contract "ANR-11-LABX-0001-01") and by the French RENATECH network through its FEMTO-ST technological facility.

\section{REFERENCES}

[1] D. Tolfree and M. Jackson, Commercializing Micro-Nanotechnology Products. CRC Press, 2006

[2] S. Bargiel, K. Rabenorosoa, C. Clévy, C. Gorecki, and P. Lutz, "Towards micro-assembly of hybrid moems components on a reconfigurable silicon free-space micro-optical bench," J. Micromech. Microeng., vol. 20, no. 4, p. 045012, April 2010.

[3] A. Das, R. Murthy, D. Popa, and H. Stephanou, "A multiscale assembly and packaging system for manufacturing of complex micro-nano devices," IEEE Trans. on Automation Science and Engineering, vol. 9, no. 1, pp. 160-170, Jan. 2012.

[4] E. Avci, K. Ohara, C.-N. Nguyen, C. Theeravithayangkura, M. Kojima, T. Tanikawa, Y. Mae, and T. Arai, "High-speed automated manipulation of microobjects using a two-fingered microhand," IEEE Trans. on Industrial Electronics, vol. 62, no. 2, pp. 1070-1079, Feb. 2015.

[5] Z. Lu, P. C. Y. Chen, A. Ganapathy, G. Zhao, J. Nam, G. Yang, E. Burdet, C. Teo, Q. Meng, and W. Lin, "A force-feedback control system for micro-assembly," J. Micromech. Microeng., vol. 16, no. 9, p. 1861, Sept. 2006.

[6] N. Chaillet and S. Régnier, Microrobotics for Micromanipulation. Wiley-ISTE, 2010.

[7] K. Rabenorosoa, C. Clévy, Q. Chen, and P. Lutz, "Study of forces during microassembly tasks using two-sensing-fingers grippers," IEEE/ASME Trans. on Mechatronics, vol. 17, no. 5, pp. 811-821, Oct. 2012.

[8] B. Komati, K. Rabenorosoa, C. Clévy, and P. Lutz, "Automated guiding task of a flexible micropart using a two-sensing-finger microgripper," IEEE Trans. on Automation, Science and Engineering, vol. 10, no. 3, pp. 515-524, July 2013.

[9] M. Rakotondrabe, I. Ivan, S. Khadraoui, P. Lutz, and N. Chaillet, "Simultaneous displacement/force self-sensing in piezoelectric actuators and applications to robust control," IEEE/ASME Trans. on Mechatronics, vol. 20, no. 2, pp. 519-531, April 2015.

[10] F. Wang, C. Liang, Y. Tian, X. Zhao, and D. Zhang, "Design of a piezoelectric-actuated microgripper with a three-stage flexure-based amplification," IEEE/ASME Trans. on Mechatronics, vol. 20, no. 5, pp. 2205-2213, Oct. 2015.
[11] T. McPherson and J. Ueda, "A force and displacement self-sensing piezoelectric mri-compatible tweezer end effector with an on-site calibration procedure," IEEE/ASME Trans. on Mechatronics, vol. 19, no. 2, pp. 755-764, April 2014.

[12] N. Dechev, W. Cleghorn, and J. Mills, "Microassembly of 3-d microstructures using a compliant, passive microgripper," J. of Microelectromech. Syst., vol. 13, no. 2, pp. 176-189, April 2004.

[13] P. de Lit, J. Agnus, C. Clévy, and N. Chaillet, "A four-degree-of-freedom microprehensile microrobot on chip," Assembly and Automation, vol. 24, no. 1, pp. 33-42, 2004.

[14] B. Piriyanont, A. Fowler, and S. Moheimani, "Force-controlled mems rotary microgripper," J. of Microelectromech. Syst., vol. 24, no. 4, pp. 1164-1172, Aug. 2015.

[15] D. Wang, Q. Yang, and H. Dong, "A monolithic compliant piezoelectricdriven microgripper: Design, modeling, and testing," IEEE/ASME Trans. on Mechatronics, vol. 18, no. 1, pp. 138-147, Feb. 2013.

[16] Q. Xu, "A new compliant microgripper with integrated position and force sensing," IEEE/ASME Int. Conf. on Advanced Intelligent Mechatronics, Wollongong, Australia, July 9-12 2013.

[17] M. Rakotondrabe and I. Ivan, "Development and force/position control of a new hybrid thermo-piezoelectric microgripper dedicated to micromanipulation tasks," IEEE Trans. on Automation Science and Engineering, vol. 8, no. 4, pp. 824-834, Oct. 2011.

[18] K. Kim, X. Liu, Y. Zhang, and Y. Sun, "Nanonewton force-controlled manipulation of biological cells using a monolithic mems microgripper with two-axis force feedback," J. Micromech. Microeng., vol. 18, no. 5, p. 055013, May 2008.

[19] T. Duc, G. Lau, J. Creemer, and P. Sarro, "Electrothermal microgripper with large jaw displacement and integrated force sensors," J. of Microelectromech. Syst., vol. 17, no. 6, pp. 1546,1555, Dec. 2008.

[20] F. Beyeler, A. Neild, S. Oberti, Y. S. D.J. Bell, J. Dual, and B. Nelson, "Monolithically fabricated microgripper with integrated force sensor for manipulating microobjects and biological cells aligned in an ultrasonic field," J. of Microelectromech. Syst., vol. 16, no. 1, pp. 7-15, Feb. 2007.

[21] Q. Xu, "Precision position/force interaction control of a piezoelectric multimorph microgripper for microassembly," IEEE Trans. on Automation Science and Engineering, vol. 10, no. 3, pp. 503-514, July 2013.

[22] FT-G Microgripper, http://www.femtotools.com/index.php?id=products$\mathrm{g}$.

[23] Q. Xu, "Design, fabrication, and testing of an mems microgripper with dual-axis force sensor," IEEE Sensors Journal, vol. 15, no. 10, pp. 60176026, Oct. 2015.

[24] M. Savia and H. N. Koivo, "Contact micromanipulation-survey of strategies," IEEE/ASME Trans. on Mechatronics, vol. 14, no. 4, pp. 504 514, Aug. 2009.

[25] K. Rabenorosoa, A. N. Das, R. Murthy, C. Clévy, D. Popa, and P. Lutz, "Precise motion control of a piezoelectric microgripper for microspectrometer assembly," ASME IDETC-CIE International Design Engineering Technical Conferences and Computers and Information in Engineering Conference, San Diego, United States, September 2009.

[26] J. Doll and B. Pruitt, "High-bandwidth piezoresistive force probes with integrated thermal actuation," J. Micromech. Microeng., vol. 22, no. 9, p. 095012, Sept. 2012.

[27] Q. Xu, "Design and development of a novel compliant gripper with integrated position and grasping/interaction force sensing," IEEE Trans. on Automation Science and Engineering, vol. PP, no. 99, pp. 1-14, 2015.

[28] F. Beyeler, S. Muntwyler, and B. Nelson, "A six-axis mems forcetorque sensor with micro-newton and nano-newtonmeter resolution," $J$. of Microelectromech. Syst., vol. 18, no. 2, pp. 433-441, April 2009.

[29] C. Clévy, M. Rakotondrabe, and N. Chaillet, Signal Measurement and Estimation Techniques for Micro and Nanotechnology. Springer, 2011.

[30] K. Rabenorosoa, C. Clévy, P. Lutz, M. Gauthier, and P. Rougeot, "Measurement of pull-off force for planar contact at the microscale," Micro Nano Letters, vol. 4, pp. 148 -154, 2009.

[31] B. Komati, J. Agnus, C. Clévy, and P. Lutz, "Prototyping of a highly performant and integrated piezoresistive force sensor for microscale applications," J. Micromech. Microeng., vol. 24, no. 3, p. 035018, March 2014.

[32] J. Choi, Z. Qiu, C.-H. Rhee, T. Wang, and K. Oldham, "A three-degreeof-freedom thin-film pzt-actuated microactuator with large out-of-plane displacement," J. Micromech. Microeng., vol. 24, no. 7, p. 075017, July 2014.

[33] X. Chen and W. Li, "A monolithic self-sensing precision stage: Design, modeling, calibration, and hysteresis compensation," IEEE/ASME Trans. on Mechatronics, vol. 20, no. 2, pp. 812-823, April 2015. 
[34] G. Gu, L. Zhu, C. Su, H. Ding, and S. Fatikow, "Proxy-based slidingmode tracking control of piezoelectric-actuated nanopositioning stages," IEEE/ASME Trans. on Mechatronics, vol. 20, no. 4, pp. 1956-1965, Aug. 2015.

[35] A. Eielsen, M. Vagia, J. Gravdahl, and K. Pettersen, "Damping and tracking control schemes for nanopositioning," IEEE/ASME Trans. on Mechatronics, vol. 19, no. 2, pp. 432-444, April 2014.

[36] J. Peng and X. Chen, "Integrated pid-based sliding mode state estimation and control for piezoelectric actuators," IEEE/ASME Trans. on Mechatronics, vol. 19, no. 1, pp. 88-99, Feb. 2014.

[37] Y. Cao and X. Chen, "Disturbance-observer-based sliding-mode control for a 3-dof nanopositioning stage," IEEE/ASME Trans. on Mechatronics, vol. 19, no. 3, pp. 924-931, June 2014.

[38] J. Peng and X. Chen, "A survey of modeling and control of piezoelectric actuators," Modern Mechanical Engineering, vol. 3, no. 1, pp. 1-20, 2013.

[39] T. Low and W. Guo, "Modeling of a three-layer piezoelectric bimorph beam with hysteresis," J. of Microelectromech. Syst., vol. 4, no. 4, pp. 230-237, Dec. 1995.

[40] J. Smits, S. Dalke, and T. Cooney, "The constituent equations of piezoelectric bimorphs," Sensors and Actuators A: Physical, vol. 28, no. 1, pp. 41-61, June 1991.

[41] M. Rakotondrabe, Y. Haddab, and P. Lutz, "Quadrilateral modelling and robust control of a nonlinear piezoelectric cantilever," IEEE Trans. on Control Systems Technology, vol. 17, no. 3, pp. 528-539, May 2009.

[42] Q. Xu and Y. Li, "Model predictive discrete-time sliding mode control of a nanopositioning piezostage without modeling hysteresis," IEEE Trans. on Control Systems Technology, vol. 20, no. 4, pp. 983-994, July 2012.

[43] B. Komati, C. Clévy, M. Rakotondrabe, and P. Lutz, "Dynamic force/position modeling of a one-dof smart piezoelectric micro-finger with sensorized end-effector," IEEE/ASME Int. Conf. on Advanced Intelligent Mechatronics, pp. 1474-1479, Besançon, July 2014.

[44] R. Ballas, Piezoelectric Multilayer Beam Bending Actuators: Static and Dynamic Behavior and Aspects of Sensor Integration. Springer, 2007.

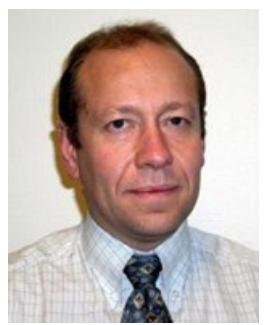

Philippe Lutz joined the University of FrancheComté, Besançon, as Professor in 2002. He was the head of the research group "Automated Systems for Micromanipulation and Micro-assembly" of the AS2M department of FEMTO-ST Institute from 2005 to 2011 . He is currently the Director of the $\mathrm{PhD}$ graduate school of Engineering science and Microsystems with more than $400 \mathrm{PhD}$ students. His research activities at FEMTO-ST are focused on the design and the control of MicroMechatronic Systems. P. Lutz received several awards of IEEE, authored over 80 refereed publications ( 35 in high standard journals), serves as associate editor for the IEEE Transaction on Automation Science and Engineering and as Technical Editor for the IEEE/ASME Transactions on Mechatronic, is member of several steering committees and is member of the IEEE Robotics and Automation Society (RAS) Committee on MicroNano Robotics. He received the Engineer degree from the National School of Mechanics and Microtechnology (ENSMM) in 1990 and the Ph.D. Degree of the University of Franche-Comté in Automation and Computer Science in 1994. He was Associate Professor in the INSA of Strasbourg since 1994 until 2002.

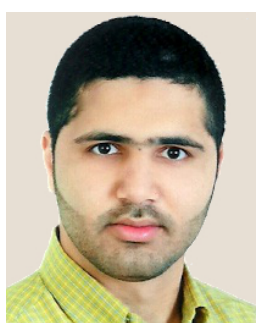

Bilal Komati received an Electrical Engineer degree from Lebanese University, Lebanon, in 2011, M.S. degree in automatic control and signal processing from Supélec, Paris, France in 2011 and the Ph.D. degree in automatic control and microrobotics from the University of Franche-Comté, Besançon, France in 2014. He is the winner of the 2014's best Ph.D. in robotics in France rewarded by the robotics research group of the French National Center for Scientific Research (CNRS). In 2015, he has been a postdoctoral researcher at the FEMTO-ST institute with the AS2M Department of Automatic Control and Micro-Mechatronic Systems.

Since 2016, he has been a research project manager at Percipio Robotics, Besançon, France, where his research interests include design, modeling and control of microrobots and micromechatronic systems for micromanipulation and microassembly.

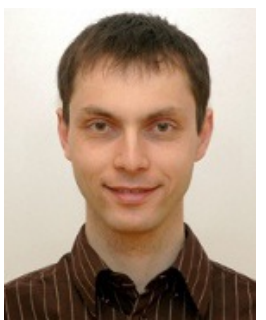

Cédric Clévy graduated from the Ecole Normale Supérieure de Cachan, France in 2001 received his Master degree of Mechanical engineering, Automatics and Automation in 2002 and his Ph. D. degree in Automatic Control and computer Sciences in 2005. Since 2006, he has been an Associate Professor at the University of Franche-Comté, Besanon, France working in the AS2M (Automatic Control and MicroMechatronic Systems) department of FEMTO-ST Institute. His research interests are the design, modeling and control of microrobotic, micromechatronic and micro-assembly systems oriented to MOEMS. 